REVIEW

\title{
The implications of the David Glass case for future clinical practice in the UK
}

\author{
A C Elias-Jones, J Samanta
}

Arch Dis Child 2005;90:822-825. doi: 10.1136/adc.2004.070672

A recent decision of the European Court of Human Rights (ECHHR)' raises issues of considerable importance to medical practitioners and paediatricians in particular. The case concerns the parental right to withhold consent to medical intervention that doctors believe to be necessary in a child's best interests. The dramatic facts of this case (in which a boy's family felt they had to fight for his life) has significant repercussions for clinical practice. This is discussed in the light of previous and recent cases that have involved babies, infants and children. The worrying trend to use the Courts to resolve these difficult clinical cases is discussed.

See end of article for authors' affiliations ....................

Correspondence to: Dr Alun Cameron EliasJones, Department of Paediatrics, Leicester Royal Infirmary, Havelock Street, Leicester LE1 5WW, UK; Alun.Elias-Jones@uhl-tr. nhs.uk

Accepted 11 May 2005
$\mathrm{T}$ he applicants to the ECtHR were David Glass (the patient) and Ms Carol Glass (his mother). David, born in1986, is severely mentally and physically disabled and has required 24 hour care and attention since birth. This has been expertly provided by his mother and extended family. David is not terminally ill and the family remains hopeful that he will live out his normal life expectancy.

David was admitted to the Portsmouth Hospitals NHS Trust in July 1998 for a tonsillectomy to treat noisy and laboured breathing. Unfortunately, his postoperative recovery was stormy. Following several complications and catastrophic events from which he was resuscitated, doctors took the view that his condition was terminal and that further intensive care would be inappropriate. The family believed otherwise and felt that the medical staff were taking a less interventional approach because David was disabled. Fortunately, David's condition improved and he was discharged home. However, he was subsequently readmitted on several occasions with respiratory infections.

During one such readmission, doctors raised the issue of palliative care to relieve pain, anxiety and distress, and suggested that opiates might be used. Ms Glass strongly objected as the family's principal concern was that this was tantamount to covert euthanasia. She emphasised that in the event of David suffering a cardiac arrest, she would expect full resuscitation with intubation. The medical view was that such measures were clinically inappropriate and not in David's best interests. An entry was recorded that if the matter could not be resolved, a second opinion would be necessary. Doctors sought the opinion of the Official Solicitor who advised that if the matter went to Court, there was no precedent of a judge overturning a doctor's decision to provide palliative care to an incompetent patient at the end of his or her life.

David's condition improved, and then relapsed; he was sent home, and readmitted. On one such occasion David was diagnosed as being in terminal respiratory failure. Diamorphine was prescribed for pain relief and to alleviate distress. Ms Glass refused to believe that David was dying, and felt that diamorphine would diminish his chances of recovery. An urgent meeting was called and attended by David's clinicians, the chief executive officer of the Trust, and a female police officer, who was present at the Trust's request. Ms Glass insisted that David be taken home to die in peace. She received a police caution that she would be arrested if she attempted to forcibly remove her son.

An infusion of diamorphine was begun later that day, as a result of which David appeared alarmingly unresponsive to his mother, although medical opinion considered him to be "peaceful and settled". Ms Glass and the family believed that they were witnessing David's impending demise. Attempts were made to revive David and a fracas broke out between the hospital staff and family members. Several injuries were sustained, the ward had to be evacuated, and the police were summoned urgently. Ms Glass herself successfully revived David, and took him home. David's general practitioner, who had maintained a good relationship with the family, took over David's medical care, to which he later responded. Subsequently, the Trust felt it necessary to obtain an injunction to prevent certain members of the family from entering the hospital, and it was arranged that David's further care should be provided by another hospital owing to the irrevocable breach of trust that had occurred. It is of note that to date David has remained alive and well and has not required any further admission to hospital.

\section{THE LEGAL ISSUES}

From Ms Glass's perspective, the hospital had incorrectly given up all hope for David. She was adamant that the decision to administer diamorphine had been wrong, and her belief has been vindicated by David's subsequent clinical progress. Her application to the High Court for judicial review regarding the legality of David's treatment was dismissed on the grounds that her

Abbreviations: ECtHR, European Court of Human Rights; RCPCH, Royal College of Paediatrics and Child Health 
complaints related to factual issues and not to procedural matters in the decision making process. Subsequently, Ms Glass's appeal to the Court of Appeal was refused. Her complaint to the General Medical Council (GMC) (about the doctors' treatment of David), and then to the police (on the grounds of the attempted murder of her son) also failed. The GMC found no evidence of serious professional misconduct and the Crown Prosecution Service did not find sufficient evidence to bring criminal proceedings against the clinicians.

Having effectively exhausted all domestic remedies, Ms Glass then brought her complaint to the ECtHR, alleging violations of a number of rights enshrined in the European Convention. These included the right to life (Article 2), the right to a fair trial (Article 6), the right to respect for private and family life (Article 8), the right to an effective remedy (Article 13), and the right not to be discriminated against in the enjoyment of the Convention rights (Article 14). The Court declared the complaints partly admissible and allowed only those under Article 8 which provides that:

- Everyone has the right to respect for his private and family life, his home, and his correspondence.

- There shall be no interference by a public authority with the exercise of this right except such as in accordance with the law and as is necessary in a democratic society in the interests of national security, public safety, or the economic wellbeing of the country, for the prevention of disorder or crime, for the protection of health or morals, or for the protection of the rights and freedoms of others.

She argued that, inter alia, the decision to administer diamorphine, as well as the placing of a "Do not resuscitate" order in David's notes without parental consent was in contravention of the law, and that the existing domestic legal framework failed to protect the interests of a disabled child adequately. The Government (on behalf of the NHS Trust) contended that David's treatment had been justified and was within established law, and that it is lawful to administer opiate therapy which may have the secondary result of shortening life if the primary intention is to relieve suffering. ${ }^{2}$ However, given the family's express objections to this treatment which might have hastened David's passage it would have been prudent to test this in the UK Court, unless the medical team felt it necessary to give the treatment to avoid immediate suffering. The circumstances had required swift action. It was also argued that an urgent application to the High Court would not have regarded parental views as being determinative of a child's best interests where such views seriously conflicted with medical opinion. It was mutually agreed that the obligation to seek the consent of parents before treating a child was not an absolute requirement.

Having reviewed the existing legislative and common law framework, ethical guidelines, and the advice of professional bodies, the ECtHR emphasised that the duty to preserve life is absolute (except where specific limitations apply). Furthermore, parental consent is paramount other than in emergency situations. In the event of parental objection, doctors would be required to seek judicial intervention. It was not doubted that the doctors' actions had been motivated by a genuine concern for their patient's welfare. However, it was held that the difference between medical and family opinion as to what action was in David's "best interests" should have been referred to the Court for resolution. The Trust failed to demonstrate a sufficient emergency that might have engaged the doctrine of necessity under which treatment could be administered, ${ }^{3}$ and bore the onus to defuse the serious difference of opinion between the doctors and the family by obtaining a declaration from the Court. The doctors' actions were not unlawful as there is a plethora of case law that enables a doctor to treat a patient in what is perceived as being in their medical best interests in circumstances where consent cannot be obtained..$^{4-7}$ However, in the judgement of the ECtHR the decision to override Ms Glass's objections to the proposed treatment, in the absence of legal authorisation, represented a material interference with her rights under Article 8, and that this was neither proportionate nor justifiable as being necessary in the public interests of a democratic society. The applicants were consequently awarded costs and damages.

\section{DISCUSSION}

The issue at the heart of this case concerns the ethical and legal dilemmas raised by parental opposition to medical care being given to a critically ill child incapable of self determination. Medical opinion held the sincere belief that a seriously disabled boy was dying, and that the intervention offered was in his "best interests". The boy's mother did not accept that her son was terminally ill, and objected to the use of opiates as palliative treatment. Her concern was in respect of the well recognised secondary effect of opiates, namely depression of the respiratory centre. The principle of "double effect" is established in law and recognised by professional bodies as meaning that although the primary intention of such treatment is to achieve a positive benefit (such as relief of pain or distress), there may be a secondary side effect which could include the hastening of death in the last stages of life. The ECtHR found that the Trust in question had breached the human rights of a mother by failing to refer a dispute of "best interests" medical care to a local Court for resolution.

The question as to what constitutes the best interests of a patient is a matter for the Court to decide when there is a conflict between medical opinion and parents or those charged with legal proxy for incompetent minors. Following Glass, this obligation is sustained on the basis of the right to respect for private and family life (Article 8 of the Convention). In emergency situations, however, the law permits treatment if the doctor believes that the treatment is vital, not withstanding the opposition of a parent. ${ }^{8-10}$ A duty falls upon Trusts to seek a declaratory ruling, where time permits, to allow the Court as a neutral arbiter to adjudicate on the situation. The reasoning for this is to allow an impartial body to make a decision that can protect the interests of the incompetent child.

However, to what extent can the Courts realistically act as impartial experts? Case law indicates that emergency applications to the High Court can be problematic principally because of time constraints. ${ }^{11}$ Furthermore, a fundamental question is whether a High Court judge, who does not have the benefit of clinical experience, could be in a better position to offer a determination of best interests than are afforded by a health care team? A child's "best interests" are not limited to their "medical" best interests, but encompass wider issues such as societal, spiritual, and welfare needs. A more comprehensive approach would be to actively solicit the views of those more widely involved in the care of the child. This would include the whole health care team (who often spend considerable time with their patients and their families), and also of the social care and support services.

The difficulties experienced by the judiciary were expressed in the recent case involving Charlotte Wyatt where Mr Justice Hedley stated:

\footnotetext{
"..Whilst the judge will be more aware than anyone of his own limitations in deciding as profound an issue as this, decision there simply has to be. It may well be that an
} 
external decision is in the end a better solution than the stark alternatives of medical or parental veto. ${ }^{\prime \prime 2}$

In the case of the Manchester conjoined twins who came from the tiny Maltese island of Gozo Mr Justice Johnson admitted publicly to agonising over his decision that condemned the weaker twin Mary to inevitable death as a result of the decision to separate her from her conjoined twin Jodie. However, until any other system of arbitration is agreed in such cases the courts are likely to be the final arbiter of the child's best interest in cases of dispute between parents and the medical/nursing team

Where time permits, a further possibility is that disputes are referred for early mediation by neutral and mutually acceptable third parties. In addition to the possible avoidance of litigation, a successful mediation may help to maintain and safeguard therapeutic relations between doctors and patients.

So, what if the Trust had sought a High Court declaration in respect of David Glass? One can only speculate as to what might have happened. Previous decisions suggest that a declaration would have been granted.5 69101213 Rarely has the Court decided to side with the parental views that were contrary to the opinion of the medical attendants, such as it did in the case of $\operatorname{Re} T,{ }^{14}$ where it supported the parents view that a liver transplant for their baby with biliary atresia was not in the best interests of their child despite a unanimous medical view that it was. This ruling, however, appears to be contrary to almost all other similar cases that have been tested in the courts despite the assertion of Sir Thomas Bingham in Re $Z,{ }^{15}$ that:

\section{"the decision of a devoted and responsible parent should be treated with the utmost respect. It should not be disregarded or lightly set aside."}

Hence, the prudent clinician, having exhausted all other avenues to reach a consensus decision with the family, will be tempted to use legal resolution of the problem, particularly in expectation of the likelihood of receiving a court's declaration that the proposed course of action in that particular case will be lawful.

However, Ms Glass's view was right in her belief of David's chance of survival. In the words of Judge Casadevall, in his separate opinion: "The facts have shown - nearly six years later and to date - that, in the particular circumstances of the present case, maternal instinct has had more weight than medical opinion." ${ }^{\prime 16}$

\section{CONCLUSIONS}

Over the last 20 years or so there has been a swing away from a paternalistic model of care towards a partnership with families to create child centred care. The families are increasingly better informed owing to media exposure, and now specifically access the internet for both medical data and the advice of family support groups. Consequently, the families are much more likely than previously to find themselves at variance with their medical advisers when their assessment of treatment benefits differ from those of the medical team.

So what impact has and is this case going to have on neonatal/paediatric practice in the future? Since the case of David Glass, two further high profile cases, involving Charlotte Wyatt and Luke Winston-Jones, have come to the High Court for a judicial review. In these cases a declaration was sought that what the doctors proposed to do in not carrying out maximal cardiorespiratory resuscitation was lawful and in the best interests of the infants in their care, even though contrary to the view of the parents. The NHS trusts involved, the medical staff, and their legal advisers are clearly wary of acting in the best interests of their patients when in disagreement with the parents without the formal legal backing of the Courts, particularly when in the case of David Glass the doctors were initially supported by the English judicial system which was then overturned in the European Court of Human Rights. In order to protect their professional position, doctors are much more likely to test their decisions in the English High Court rather than run the peril of seeing their stance challenged in the European Court system at a later date. So far when tested in the UK Courts it appears that human rights considerations will not override the test of the paramount best interests of the child as stated in the Children Act. ${ }^{17}$ Furthermore it does not seem as though this decision will affect the guidance given in the RCPCH framework ${ }^{18}$ but it highlights the difficulty in determining in the individual case what are the child's best interests. This case followed the advice that in the framework (18:para 3.4.3) that in conflict a second opinion should normally be offered and the parent should be allowed time to consult advisers of their choice but when the second opinion was refused the team then imposed their favoured treatment option, with the resultant conflict.

However, even judges have alluded to their difficulty in reaching a just decision in these hard cases and this lends credence to the view that a better system than legal confrontation should be used to decide these cases where the life of an infant hangs in the balance. Are there alternative procedures that could be used to avoid recourse to the legal system in the glare of a media circus? Perhaps the recent development of clinical ethics teams can be used within the local hospital to help families and the medical care team resolve conflicts. Clinical ethics networks might be employed to settle difficulties by providing external independent advice to help resolve the conflicts that occur.

Overall the general rule should be that those with parental responsibility should decide the best interests of their child unless clearly not acting in the best interests of the child and demanding treatments that are futile. Similar decisions have been reached in the UK Courts such as where the respect for a patient's autonomous decision not to have artificial hydration and nutrition withdrawn against his consent was upheld. ${ }^{19}$

Where difficult decisions are needed, the wider involvement of the health care team and the child's family will serve to enhance the quality of the final decision..$^{20}$ This case highlights the importance of discussing and agreeing "Do not resuscitate" decisions with the families and if this is not possible, resorting to the Court rather than making a unilateral decision at variance with the carer family. As this case has shown some seven years later, maternal instinct may be more accurate than medical expertise.

As in all these difficult clinical cases, what we learn from the decision in the case of David Glass is neatly summarised by Professor Norval Morris:

\section{"In sum, the current case law and statutes do not give any clear guidance (to resolve) the problem. They tell you the principles to apply but not how these principles apply to your case."}

\section{Authors' affiliations}

A C Elias-Jones, Department of Paediatrics, University Hospitals of Leicester NHS Trust, Leicester, UK

J Samanta, Lecturer in Medical Law, De Montfort University, Leicester

Competing interests: none declared 


\section{REFERENCES}

1 Glass v UK (Application No 61827/00) [2004] 1 FCR 553.

2 R v Bodkin Adams [1957] CLR (CCC).

3 Re F (mental patient: sterilisation)[1990] 2 AC 1 (HL).

$4 \operatorname{Re} B$ (A minor)(Wardship: Medical Treatment)[1981] 1 WLR 1421.

$5 \operatorname{Re}$ C (A minor)(Wardship: Medical Treatment)[1 1989] 2 All ER 782.

6 Re J (A minor)(Wardship: Medical Treatment)[1990] 3 All ER 930.

$7 \operatorname{Re} R$ (1991) 7 BMLR 147.

8 Gillick $v$ West Norfolk and Wisbech AHA[1985] 3 All ER 402 per Lord Templeman at 432.

$9 \operatorname{Re}$ C (A minor; HIV treatment) High Court, 3/9/ 1999.

10 Re A (Conjoined twins: Medical treatment)[2001] IFLR 1.

11 St George's Healthcare NHS Trust v S[1998] 3 All ER 673 (CA).

12 NHS Trust v C. The Times 8/10/2004 at 6 .
13 NHS Trust v D. The Times LR 19/7/ 2000.

$14 \operatorname{Re} T$ (a minor)(wardship: medical treatment) [1996] 35 BMLR 63 (CA).

$15 \operatorname{Re} Z$ (a minor) (freedom of publication)[1996] 1 FLR 191 at 217.

$16 \operatorname{Re} Z$ (a minor) (freedom of publication)[1996] 1: Separate opinion of Judge Casadevall: paragraph 2.

17 Dawson $v$ Wearmouth [1999] 1 FLR 1167.

$18 \mathrm{RCPCH}$. Framework for withholding or withdrawing life-sustaining treatment in childhood. London: Royal College of Paediatrics and Child Health, 2004.

19 R (Burke) v General Medical Council (2004) Lloyds L R: Medical 451 (QBD).

20 Hagger LE. The Human Rights Act 1998 and medical treatment; time for re-examination. Arch Dis Child 2004;89:460-3.

21 The Brothel Boy and other parables of the law 1998:45.

\section{IMAGES IN PAEDIATRICS}

\section{Unusual foreign body detected on routine dental radiograph}

F requently, foreign bodies are found in the oral ${ }^{1}$ and nasal cavities of children, ${ }^{2}$ and are discovered by the dentist during routine examinations. ${ }^{23}$ These objects may be the result of the child's own action ${ }^{2}$ and may cause pain, ${ }^{2}$ oedema, and tooth fracture.

A 10 year old female came to a clinic of a Brazilian university for a dental appointment. The clinical examination indicated a large caries lesion in the first lower left deciduous molar. The tooth was very mobile, although the child did not report pain in the region. After a radiograph of the tooth, significant resorption of the roots was noted. In the pulp chamber there was a well defined cylindrical radiopaque area, measuring approximately $3.5 \mathrm{~mm} \times$ $1.5 \mathrm{~mm}$ (fig 1). It was decided to extract the tooth, and after inspecting it a small metal screw was found firmly embedded in it (fig 2). When the patient was questioned, she reported that a week earlier she had tried to tighten the screw of her spectacles with her teeth, but thought she had lost the screw, thus not knowing that it was in her mouth. After one week, the patient returned for a surgery check-up, then was discharged for six months. One year later, it was found that the first lower left premolar had erupted normally (fig 3 ).

Health professionals should be alert to the presence of foreign bodies, and educational campaigns should be conducted for emphasising the dangers of improper use of teeth.

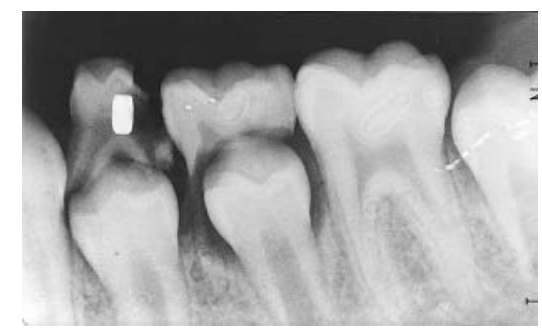

Figure 1 Periapical radiograph showing a radiopaque area in the region of the pulp chamber.

L Pomarico

Veiga de Almeida University, Rio de Janeiro, Brazil

L G Primo, I P R de Souza Department of Pediatric Dentistry and Orthodontics, Federal University of Rio de Janeiro, Rio de Janeiro, Brazil

Correspondence to: Dr L Pomarico, Praia do Flamengo 370/202-Flamengo, 22210-030

Rio de Janeiro, RJ, Brazil; lupomarico@superig.com.br

Competing interests: none declared

Consent was obtained for publication of all figures.

\section{References}

1 Ram D, Peretz B. Tongue piercing and insertion of metal studs: three cases of dental and oral consequences. ASDC J Dent Child 2000;67:326-9

2 Tay ABG. Long-standing intranasal foreign body: an incidental finding on dental radiograph: a case report and literature review. Oral Surg Oral Med Oral Pathol Oral Radiol Endod 1990:4:546-9.

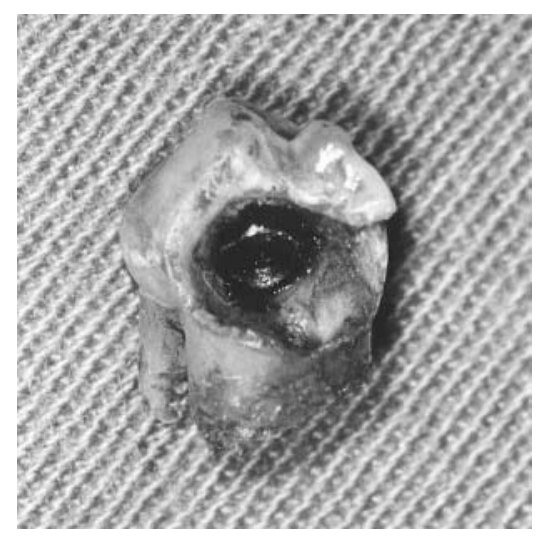

Figure 2 First lower left deciduous molar after extraction with a foreign metallic body inside the pulp chamber.

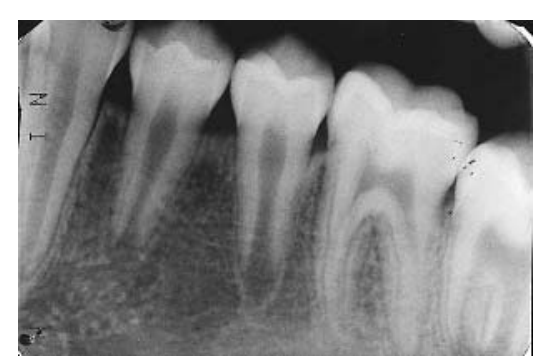

Figure 3 Periapical radiograph showing eruption of the lower left premolars.

3 Yassin OM, Hattab FN. Unusual nasal foreign body detected on routine dental radiography: case report. J Clin Pediatr Dent 1996;20:155-7. 